\title{
Introduction: Harnessing the Power of Grey
}

\author{
Dominic J. Farace
}

Published online: 15 June 2007

(C) Springer Science+Business Media, LLC 2007

Grey Literature is defined as "Information produced on all levels of government, academics, business and industry in electronic and print formats not controlled by commercial publishing i.e. where publishing is not the primary activity of the producing body" (Luxembourg, 1997-Expanded in New York, 2004).

The Eighth International Conference on Grey Literature (GL8) entitled "Harnessing the Power of Grey" offered a global platform situated and constructed for the R\&D community. One focused on the state of the art in grey literature with applications and innovative uses in and for science and technology. This special issue of Publishing Research Quarterly, which I have the pleasure of guest editing, provides a selection of papers from the conference series.

In Part One, four articles deal with water management in coastal and aquatic environments. GL8 provided a solid platform in a metropolitan city devastated by Hurricane Katrina. This city and coastal region is now in the throws of reconstruction unprecedented in recent history. The grey literature community was offered a tiered challenge last December in New Orleans. They were asked to demonstrate the state of the art in their field. They were encouraged to incorporate new and emerging areas in grey S\&T. And, they were charged to address echelons within their own organizations responsible for the appropriation of material and human resources.

In Part Two, four articles deal with requirements for access to grey literature in electronic environments. The key issues of repositories and metadata are dealt with in contexts ranging from aerospace to public health.

D. J. Farace $(\bowtie)$

TextRelease/GreyNet, Grey Literature Network Service,

Javastraat 194-HS, Amsterdam 1095 CP, The Netherlands

e-mail: dominic.farace@textrelease.com 
I invite you to read this selection of articles; and on behalf of the authors I welcome your thoughts and ideas. Likewise, on behalf of the Flemish Government, I invite you to attend the Ninth International Conference on Grey Literature (GL9) that will be held in Antwerp, Belgium on 10-11 December 2007. 